\title{
The small GTPase CDC42 regulates actin dynamics during porcine oocyte maturation
}

\author{
Yu ZHANG ${ }^{1)}$, Qiao-Chu WANG ${ }^{1)}$, Jun LIU1), Bo XIONG ${ }^{1)}$, Xiang-Shun $\mathrm{CUI}^{2}$, \\ Nam-Hyung $\mathrm{KIM}^{2)}$ and Shao-Chen SUN ${ }^{1)}$ \\ ${ }^{1)}$ College of Animal Science and Technology, Nanjing Agricultural University, Nanjing 210095, China \\ ${ }^{2)}$ Department of Animal Sciences, Chungbuk National University, Cheongju 361-763, Korea
}

\begin{abstract}
The mammalian oocyte undergoes an asymmetric division during meiotic maturation, producing a small polar body and a haploid gamete. This process involves the dynamics of actin filaments, and the guanosine triphosphatase (GTPase) protein superfamily is a major regulator of actin assembly. In the present study, the small GTPase CDC42 was shown to participate in the meiotic maturation of porcine oocytes. Immunofluorescent staining showed that CDC42 was mainly localized at the periphery of the oocytes, and accumulated with microtubules. Deactivation of CDC42 protein activity with the effective inhibitor ML141 caused a decrease in actin distribution in the cortex, which resulted in a failure of polar body extrusion. Moreover, western blot analysis revealed that besides the Cdc42-N-WASP pathway previously reported in mouse oocytes, the expression of ROCK and p-cofilin, two molecules involved in actin dynamics, was also decreased after CDC42 inhibition during porcine oocyte maturation. Thus, our study demonstrates that CDC42 is an indispensable protein during porcine oocyte meiosis, and CDC42 may interact with N-WASP, ROCK, and cofilin in the assembly of actin filaments during porcine oocyte maturation.
\end{abstract}

Key words: Actin, CDC42, Meiosis, Oocyte, ROCK

(J. Reprod. Dev. 63: 505-510, 2017)

$\mathbf{T}$ he maturation of mammalian oocytes is distinguished from somatic cell division; in the porcine oocyte, the first meiotic division generates a small polar body (PB1) and a large metaphase II (MII)-arrested oocyte. Only after fertilization will the oocyte begin its second meiotic division. Both of these processes are strongly asymmetric and are driven by the eccentric positioning of the spindle. During meiosis, after germinal vesicle break down (GVBD), a bipolar spindle forms in the cytoplasm of the oocyte and then anchors near the cortical region $[1,2]$. Meanwhile, the microvilli and microfilaments differentiate, which results in a microfilament-accumulated region (actin cap) and a cortical granule-free domain (CGFD) [3, 4]. When migration is completed, the chromosomes segregate, and the polar body is extruded. The segregation of homologous chromosomes in meiosis I relies on the pulling forces of microtubules [5]. Together with meiosis II, these asymmetric divisions ensure the formation of haploid gametes and sufficient cytoplasm to provide for early embryonic development [6].

The small guanosine triphosphatase (GTPase) superfamily of proteins, which are generally $20-25 \mathrm{kDa}$ in size and can be mainly divided into the Ras, Rab, Arf, Rho, and Ran subfamilies, oscillate between GTP-bound (active) and GDP-bound (inactive) states [7].

Received: March 14, 2017

Accepted: July 14, 2017

Published online in J-STAGE: August 5, 2017

(C)2017 by the Society for Reproduction and Development

Correspondence: S-C Sun (e-mail: sunsc@njau.edu.cn)

This is an open-access article distributed under the terms of the Creative Commons Attribution Non-Commercial No Derivatives (by-nc-nd) License. (CC-BY-NC-ND 4.0: https://creativecommons.org/licenses/by-nc-nd/4.0/)
Guanine-nucleotide exchange factors (GEFs) and GTPase-activating proteins (GAPs) control this process [8,9]. At least 20 Rho GTPases have been identified in humans, among which, RhoA, Rac1, and CDC42 are the most well studied [10]. In addition to controlling enzymatic activities and gene expression, Rho GTPases are also involved in actin and microtubule dynamics, which control numerous actin-based cellular processes, such as cell migration and polarity, endocytosis, and vesicle trafficking [11-13].

Actin microfilaments are known to be involved in spindle migration and anchoring during oocyte maturation. When spindle migration initiates, the network of actin filaments becomes denser at the periphery of the oocyte to form an actin cap [2, 14, 15]. Cell division cycle 42 (CDC42) belongs to the Rho subfamily, and it plays an indispensable role in cell motility, proliferation, apoptosis, and especially microfilament-dependent cell polarity [16]. CDC42 is known to interact with PAR proteins in the establishment of polarity in neuronal cells and embryos $[17,18]$. A recent study found that CDC42 deletion causes a failure of actin localization and organization, which leads to a loss of endothelial polarity [19]. In addition to its cooperation with actin, CDC42 also regulates the polarity of hair cell planar through microtubules in the developing cochlea [20]. The role of CDC42 in the plasma membrane in different species has been examined. In Xenopus oocytes, CDC42 downregulates the ARP2/3 complex to inhibit membrane protrusion [21], and in mouse oocytes and embryos, CDC42 is involved in cytokinesis as the upstream mediator of IQGAP1 [22]. In meiosis II of mouse oocytes, inhibition of CDC42 resulted in the release of N-WASP into the cytosol and a failure of second polar body extrusion [23]. It is well known that CDC42 mediates spindle positioning during in vitro maturation; 
however, a recent in vivo study showed that failure of polar body emission is caused by disruption of polarity and cytokinesis rather than spindle migration/organization [24].

Although the roles of CDC42 have been examined in other systems, even mouse oocytes, how it functions in porcine oocyte maturation is unknown. The present study of CDC42 in porcine oocytes will enrich our understanding of the roles of CDC42 among different species. In addition, the porcine oocyte is more similar to the human oocyte than the mouse oocyte in many respects. The relative volume of the human oocyte is close to that of a porcine egg $(120-125 \mu \mathrm{m}$ in diameter), both of which are larger than the mean size of the mouse oocyte $(\sim 80 \mu \mathrm{m}$ in diameter) $[25,26]$. Moreover, the average time for oocyte maturation in pigs and humans is also similar; it takes $40-44 \mathrm{~h}$ for a porcine oocyte and $40 \mathrm{~h}$ for a human oocyte to mature, which this is more than 3 -times longer than the average maturation time for mouse oocytes $[25,27]$. In addition to these physiological similarities, recent studies showed that the core transcriptional network required to maintain pluripotency and self-renewal in the pig is markedly similar to that in humans, but differs from that of the mouse [28]. Accordingly, the developmental stage of embryonic genome activation in humans is also more similar to pigs than mice $[29,30]$. Pig oocytes and embryos have a large quantity of endogenous lipids, which may account for oocyte developmental competence and ATP content during meiotic maturation [31]. Furthermore, the size of a porcine oocyte is much larger, whereas the spindle in the mouse oocyte is much smaller, which means that a longer distance is required for actin-mediated spindle migration during meiosis in porcine oocytes. These characteristics make the porcine oocyte a good model for livestock animals and humans compared with the mouse.

Here, we explored the expression, localization, and function of CDC42 during meiotic maturation of porcine oocytes. Our results showed that CDC42 may interact with N-WASP, ROCK, and cofilin during actin-based polar body emission.

\section{Materials and Methods}

\section{Antibodies and chemicals}

Primary antibodies: a rabbit polyclonal anti-CDC42 antibody and rabbit monoclonal anti-N-WASP antibody were purchased from Abcam (Cambridge, UK); a rabbit polyclonal anti-ROCK antibody was purchased from Santa Cruz (Santa Cruz, CA, USA); a rabbit monoclonal anti-p-cofilin antibody and a rabbit polyclonal anti- $\alpha$ tubulin antibody were purchased from Cell Signaling Technology (Danvers, MA, USA). Secondary antibodies: goat anti-rabbit IgG/ FITC and goat anti-rabbit IgG/TRITC were purchased from Zhongshan Golden Bridge Biotechnology (Beijing, China); HRP-conjugated Pierce goat anti-rabbit IgG was purchased from Cell Signaling Technology. Chemicals: all chemicals used in this study were obtained from Sigma Chemical Company (St. Louis, MO, USA), unless otherwise specified, and ML141, a potent, selective inhibitor of CDC42, was purchased from Santa Cruz.

\section{Oocyte harvest and in vitro maturation}

All animal manipulations were conducted in accordance with the guidelines of the Animal Research Committee of Nanjing Agricultural University, China. This study was approved by the Committee of
Animal Research Institute, Nanjing Agricultural University, China. Ovaries were collected from prepubertal gilts at a local slaughterhouse, placed in $0.9 \%$ physiological saline in a thermos bottle and transported to our laboratory within $2 \mathrm{~h}$. Isolation and selection of cumulus-oocyte complexes (COCs) was as described previously. The medium used for maturation culture was improved TCM-199 supplemented with $75 \mu \mathrm{g} / \mathrm{ml}$ penicillin, $50 \mu \mathrm{g} / \mathrm{ml}$ streptomycin, 0.5 $\mu \mathrm{g} / \mathrm{ml} \mathrm{FSH}, 0.5 \mu \mathrm{g} / \mathrm{ml} \mathrm{LH}, 10 \mathrm{ng} / \mathrm{ml}$ epidermal growth factor (EGF), and $0.57 \mathrm{mM}$ cysteine. Oocytes were cultured in $500 \mu \mathrm{l}$ of maturation medium covered with a thin layer of mineral oil at $38.5^{\circ} \mathrm{C}$ for 27 or $44 \mathrm{~h}$ in a humidified atmosphere of $5 \% \mathrm{CO}_{2}$ in a four-well culture dish (Nunc, Roskilde, Denmark). We used an inverted microscope $(200 \times)$ to check the polar body, and we rotated the oocytes to ensure proper judgment.

\section{ML141 treatment}

ML141 was dissolved in DMSO to $50 \mathrm{mM}$ for storage, and then ML141 was diluted in maturation medium to final concentrations of 20 and $40 \mu \mathrm{M}$, with less than $1 \%$ DMSO in the medium. The oocytes were treated with ML141 from the beginning of cultivation, at the GV stage. We cultured the oocytes for 27 and $44 \mathrm{~h}$ to obtain MI and MII stage oocytes, respectively.

\section{Oocyte nocodazole treatment}

For nocodazole treatment, a $10 \mathrm{mg} / \mathrm{ml}$ nocodazole stock (in DMSO) was diluted with TCM-199 to a working concentration of $20 \mu \mathrm{g} / \mathrm{ml}$. After $10 \mathrm{~min}$ of incubation, the oocytes were used for immunofluorescence microscopy.

\section{Immunofluorescence staining}

After culture for 27 or $44 \mathrm{~h}$, cumulus cells were removed by repeated pipetting. Denuded oocytes were first fixed with $4 \%$ paraformaldehyde for $30 \mathrm{~min}$ and then permeabilized with $1 \%$ Triton $\mathrm{X}-100$ at room temperature for at least $8 \mathrm{~h}$. After blocking with $1 \%$ BSA-supplemented phosphate-buffered saline (PBS) for $1 \mathrm{~h}$, oocytes were incubated with a rabbit polyclonal anti-CDC42 antibody (1:200) at $4^{\circ} \mathrm{C}$ overnight. After three washes in washing buffer $(0.1 \%$ Tween 20 and $0.01 \%$ Triton X-100 in PBS), oocytes were stained with a FITC-anti-rabbit IgG or TRITC-anti-rabbit IgG (1:100) for $1 \mathrm{~h}$ at room temperature. For $\alpha$-tubulin-FITC and Phalloidin-TRITC staining, after incubation for $1 \mathrm{~h}$, oocytes were washed three times (2 min per wash) in PBS containing $0.1 \%$ Tween 20 and $0.01 \%$ Triton X-100. Samples were then co-stained with Hoechst $33342(10 \mu \mathrm{g} / \mathrm{ml}$ in PBS) for $10 \mathrm{~min}$. Oocytes were mounted on slides and examined with a confocal laser-scanning microscope (Zeiss LSM 700 META, Germany). Each experiment was repeated at least 3 times, and at least 10 oocytes were examined.

\section{Western blot analysis}

To detect the levels of ROCK, p-cofilin, and N-WASP, 120 denuded porcine oocytes were collected after culturing for $27 \mathrm{~h}$, lysed in Laemmli sample buffer (SDS sample buffer containing 2-mercaptoethanol), boiled at $100^{\circ} \mathrm{C}$ for $10 \mathrm{~min}$, and immediately frozen at $-20^{\circ} \mathrm{C}$ until use. Total proteins were loaded on a $12 \%$ SDS-PAGE gel (Invitrogen, NY, USA) for $1 \mathrm{~h}$ at $200 \mathrm{~V}$ and $4{ }^{\circ} \mathrm{C}$, and then transferred to a polyvinylidene fluoride (PVDF) membrane 
(Invitrogen) for $1 \mathrm{~h}$ at $30 \mathrm{~V}$ and $4^{\circ} \mathrm{C}$. Membranes were blocked with $5 \%$ nonfat dry milk in Tris-buffered saline containing $0.1 \%$ Tween 20 (TBST) for $1 \mathrm{~h}$, and then incubated with anti-CDC42, p-cofilin, and N-WASP antibodies overnight at $4{ }^{\circ} \mathrm{C}$. After washing three times in TBST (10 min each), the membranes were incubated at room temperature for $1 \mathrm{~h}$ with HRP-conjugated Pierce goat anti-rabbit IgG (1:1000). Finally, the membranes were processed with high-sig ECL western blotting substrate (Tannon, China). Equal protein loading was confirmed by detection of $\alpha$-tubulin.

\section{Statistical analysis}

For each treatment, at least three replicates were tested, and the results are reported as mean \pm SEM. Statistical comparisons were made by independent-sample $t$-tests using SPSS 12.0 statistical software. Results were considered significant at $\mathrm{P}<0.05$.

\section{Results}

\section{Expression and localization of CDC42 in porcine oocytes during maturation}

We first examined the expression and localization of CDC42 during maturation of porcine oocytes by immunofluorescence. As shown in Fig. 1A, CDC42 was localized to the cortex of porcine oocytes during meiosis. At the germinal vesicle (GV) stage, the CDC42 signal was detected around the GVs. As the oocytes developed and the spindle formed in the MI and MII stages, CDC42 was accumulated with the spindle. Double staining of CDC42 and microtubules showed that CDC42 was co-localized with microtubules during the AI-TI stage (Fig. 1B). After treatment with nocodazole (a drug that inhibits the dynamics of microtubules), the specific localization of CDC42 disappeared (Fig. 1C). CDC42 and actin double staining showed that CDC42 was co-localized with actin (Fig. 1D).

\section{ML141 treatment results in a failure of polar body extrusion}

Next, we studied the functions of CDC42 during porcine oocyte maturation by treating oocytes with a non-competitive inhibitor of CDC42 (ML141) that inhibits GTP binding and inactivates its functions [32]. After treatment with ML141 for $27 \mathrm{~h}$, the specific localization pattern of CDC42 in the vicinity of the spindle and at the periphery of the oocytes disappeared, which confirmed the inhibitory effects of ML141 on CDC42 activity (Fig. 2A). Then, we cultured porcine oocytes with ML141 for $44 \mathrm{~h}$ to inhibit the formation of active GTP-CDC42. As expected, most control oocytes had extruded small polar bodies and were arrested at the MII stage. ML141 treatment suppressed porcine polar body extrusion, and most treated oocytes had no polar body (Fig. 2B). Moreover, the rate of polar body extrusion was significantly decreased. The statistical analysis showed that only $57.67 \pm 7.41 \%(\mathrm{n}=172)$ of oocytes in the $20 \mu \mathrm{M}$ treatment group and $44.78 \pm 4.98 \%(\mathrm{n}=171)$ in the 40 $\mu \mathrm{M}$ treatment group extruded polar bodies, which was significantly lower than that in the control group $(83.46 \pm 2.51 \%, \mathrm{n}=161, \mathrm{P}<$ 0.05 ; Fig. 2B).

\section{ML141 treatment inhibits actin assembly}

Based on the known roles of CDC42 on actin filaments in mitotic systems, fluorescence staining was employed to examine the actin
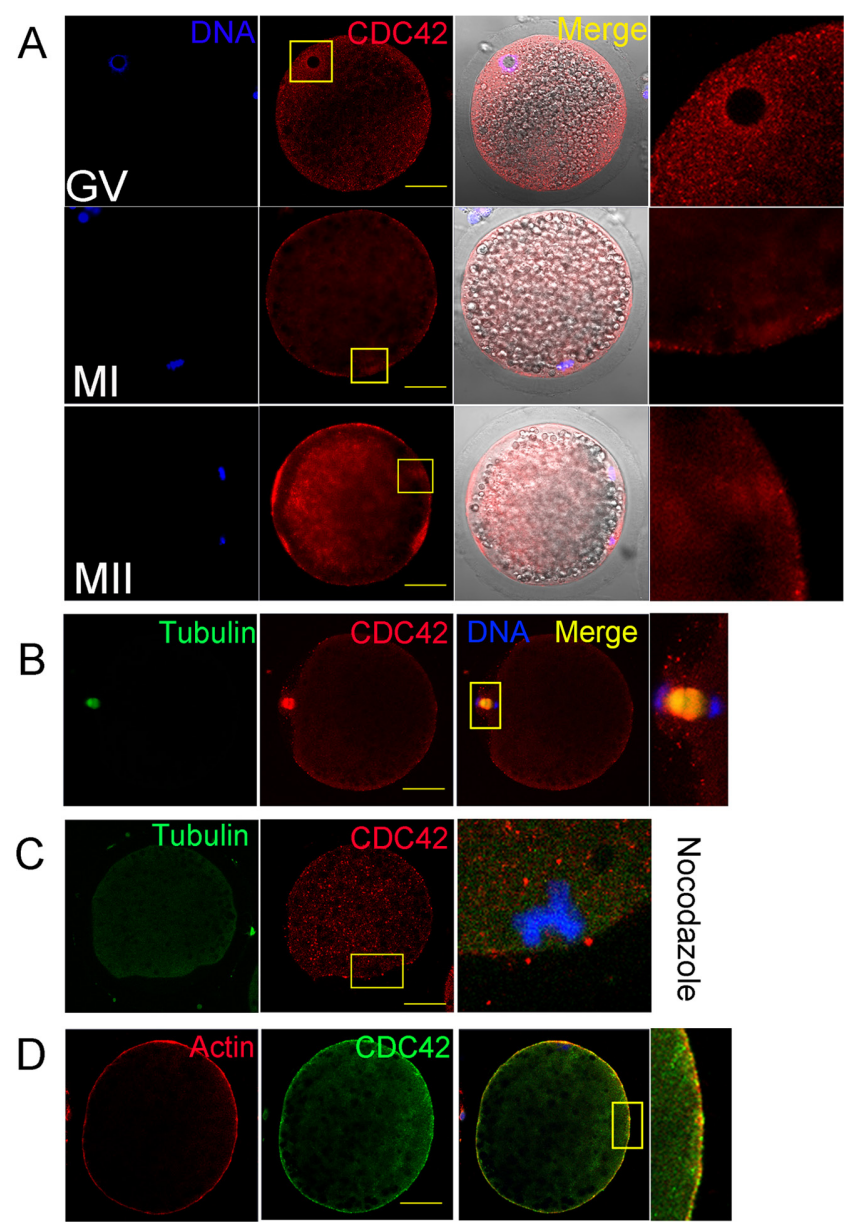

Fig. 1. The expression and localization of CDC42 during porcine oocyte maturation. (A) CDC42 is localized to the cortex of porcine oocytes during meiosis and accumulated with the porcine spindle in metaphase I (MI) and II (MII). Bar $=40 \mu \mathrm{m}$. The box shows the enlarged area of the nucleus or chromosomes. (B) CDC42 accumulates with microtubules at anaphase $\mathrm{I}$ in porcine oocytes. Bar $=40 \mu \mathrm{m}$. (C) After nocodazole treatment, the specific localization of CDC42 around the spindle in MI stage oocytes disappears. Bar $=40 \mu \mathrm{m}$. (D) CDC42 exhibits a localization pattern similar to that of Actin in MI stage oocytes. Bar $=40 \mu \mathrm{m}$.

dynamics during oocyte maturation. We added ML141 to the culture medium at the GV stage, and after treatment for $27 \mathrm{~h}$, we collected the porcine oocytes (at MI stage) for analysis. To assess actin expression after treatment, the fluorescent intensity was measured with Image J software. Control and treated oocytes were mounted on the same slide to standardize the fluorescence measurement. As shown in Fig. $3 \mathrm{~A}$, the actin signals at the membrane of most control oocytes were much stronger than those in treated oocytes. Fluorescence intensity analysis confirmed these results (control 1.0, $\mathrm{n}=30$ versus treated $0.26 \pm 0.08, \mathrm{n}=32 ; \mathrm{P}<0.05$; Fig. 3B).

Disruption of CDC42 activity causes decreased ROCK, p-cofilin, and N-WASP expression

To further investigate the mechanism of $\mathrm{CDC} 42$ in porcine oocyte 


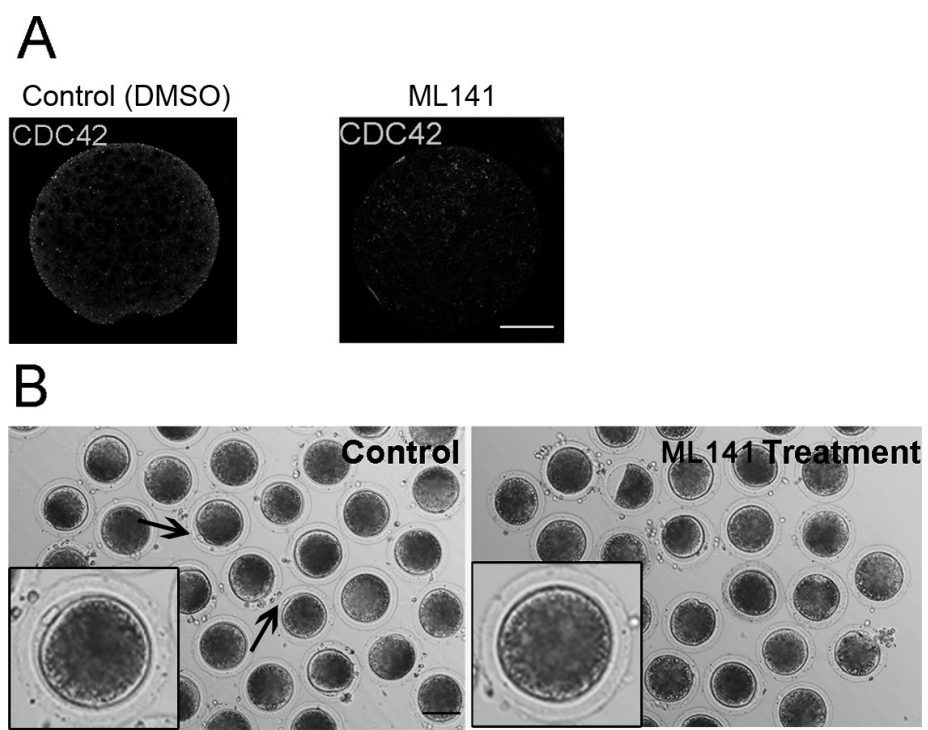

The rate of polar body extrusion

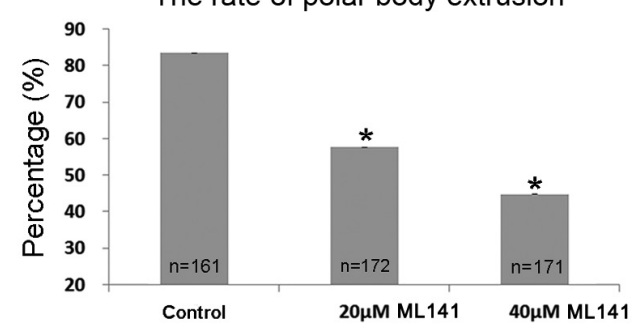

Fig. 2. The effect of ML141 treatment during porcine in vitro maturation (IVM) on CDC42 expression and polar body extrusion. (A) After ML141 treatment $(40 \mu \mathrm{M})$ for $27 \mathrm{~h}$ of IVM, the specific localization of CDC42 disappears. Bar $=40 \mu \mathrm{m}$. (B) After ML141 treatment for $44 \mathrm{~h}$ during IVM, the oocytes failed to extrude polar bodies. The rates of polar body extrusion after inhibitor treatment decreased significantly following ML141 treatment. The arrows indicate the polar bodies. Asterisks indicate significant differences. $\mathrm{Bar}=100 \mu \mathrm{m}$.
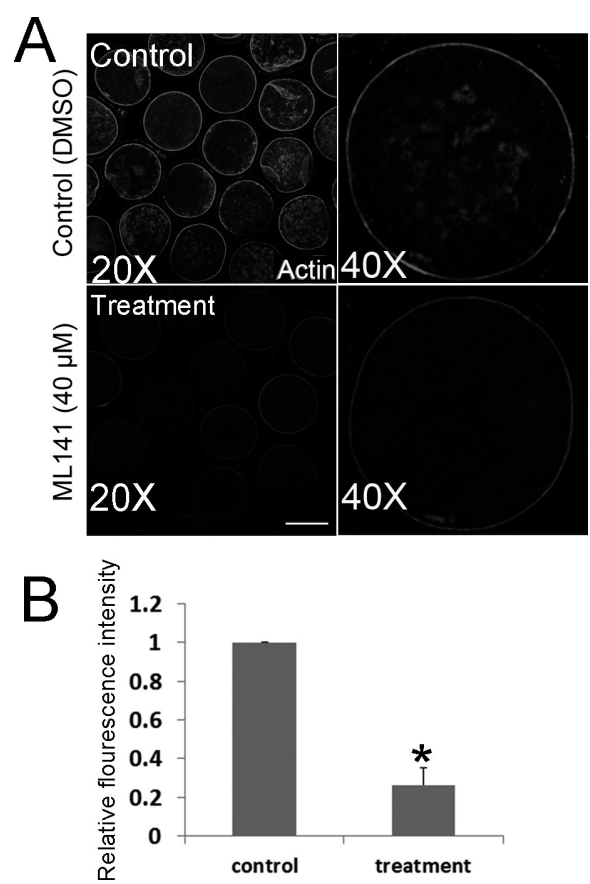

Fig. 3. ML141 treatment affects Actin expression during porcine IVM. (A) After ML141 treatment $(40 \mu \mathrm{M})$ for $27 \mathrm{~h}$ of IVM, Actin expression at the membrane declined. Bar $=40 \mu \mathrm{m}$. (B) The actin fluorescence intensity in control oocytes is significantly higher than that in oocytes treated with ML141 for $27 \mathrm{~h}$ during IVM $(\mathrm{P}<0.05)$. maturation, we examined the expression levels of ROCK, p-cofilin, and N-WASP after ML141 treatment for $27 \mathrm{~h}$. Relative intensity analysis of the western blotting results in Fig. 4A demonstrated that, after ML141 treatment, the expression levels of N-WASP decreased (control, 1.0; treated, $0.590 \pm 0.282 ; \mathrm{P}<0.05$ ). The relative intensity analysis also showed that the expression level of ROCK was significantly reduced [control, 1.0; treated, $0.582 \pm 0.101$; $\mathrm{P}<$ 0.05 ; Fig. 4B (a)]. The phosphorylation level of cofilin in treated oocytes $(0.477 \pm 0.169)$ was also lower than that in control oocytes [1.0; P $<0.05$; Fig. 4B (b)].

\section{Discussion}

In this study, we demonstrated that the small GTPase CDC42 regulates actin dynamics during maturation of porcine oocytes. Our results showed that $\mathrm{CDC} 42$ downregulates ROCK, cofilin, and N-WASP to promote the process of polar body extrusion.

To explore the mechanism of CDC42 action during porcine oocyte meiotic maturation, we first examined the localization of CDC42. The results showed that CDC42 mainly accumulated at the periphery of the oocytes throughout the maturation process, and this localization pattern was similar to that of actin, which was confirmed by double staining of actin and CDC42. A similar localization CDC42 pattern was detected in mouse oocytes [23]. A previous study showed that when the activation of CDC42 was inhibited with $\mathrm{CDC} 42 \mathrm{~T} 17 \mathrm{~N}$, a dominant-negative encoding cRNA, the F-actin-rich protrusions were absent [23]. Actin is known to be involved in cytokinesis. Thus, we inferred CDC42 might be involved in porcine oocyte maturation via an actin-based pathway.

To confirm this hypothesis, we cultured oocytes with ML141 for $42 \mathrm{~h}$ to monitor polar body extrusion. ML141 is a newly discovered, potent, selective, reversible non-competitive inhibitor of CDC42 that inhibits GTP binding and inactivates its functions [32]. ML141 was used to identify the dispensable role of CDC42 in the invasion of intestinal epithelial cells [33], and to prove that transforming growth factor $\beta$ (TGF $\beta)$ is a critical regulator of superficial zone protein production through cytoskeleton regulation [34]. Treatment with the ML141 inhibitor reduced the rate of polar body extrusion in a 

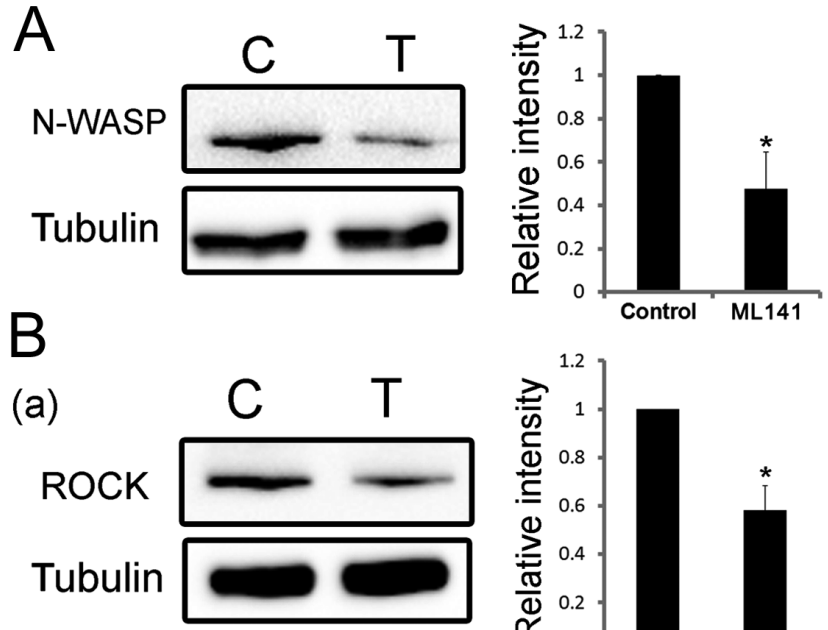

(a)

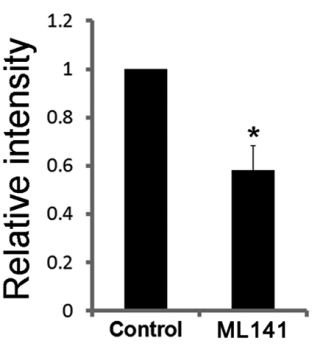

(b)

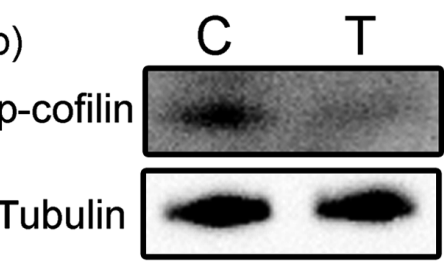

Fig. 4. The expression levels of N-WASP, ROCK, and p-cofilin decrease after deactivating CDC42 in metaphase I oocytes. (A) Western blotting showing that the expression level of N-WASP decreased and the relative intensity in treated oocytes is significantly lower than that in control oocytes $(\mathrm{P}<0.05)$. (B) Western blot results showing that the expression level of ROCK (a) and the phosphorylation level of cofilin (b) decrease and that the relative intensity in treated oocytes is significantly lower than that in control oocytes $(\mathrm{P}<0.05)$. These experiments were repeated at least three times using different samples.

dose-dependent manner. As the concentration of ML141 increased, the rate of mature oocytes decreased. This result prompted us to determine the cause of polar body extrusion failure.

The driving force of cytokinesis in cells is mainly provided by actin [35], and protrusion of the polar body is regulated by actin dynamics in Xenopus [21] and mouse oocytes [36]. A previous study showed that inhibition of $\mathrm{CDC} 42$ led to a loss of the actin cap and a failure of second polar body extrusion in mice [23]. CDC42 was co-localized with actin at the cortex, as described above. We hypothesized that the failure of polar body extrusion was due to the eccentricity of actin dynamics. As expected, the actin fluorescence intensity at the membrane in the ML141-treated group was significantly lower than that in the control group. This indicates that the dynamics of actin filaments is affected when GTP-CDC42 activity is inhibited. Thus, the aberrant assembly of actin filaments may be responsible for the failure of polar body extrusion. The result is in accordance with the findings for RhoA, another small GTPase of the Rho family; its inhibition causes oocyte immaturity and non-development of embryos in pig and mouse [37, 38].

Rho GTPase is known to be involved in mouse oocyte maturation. As a Rho GTPase effector, ROCK has been reported to cooperate with $\mathrm{CDC} 42$ and $\mathrm{CDC} 42 / \mathrm{MRCK}$ in microglial cell function [39] and myosin phosphorylation, respectively [40]. Recently, ROCK has been shown to be involved in actin-mediated cytokinesis during mouse oocyte meiosis [41]. Furthermore, cofilin, a downstream small molecule of ROCK, is also related to actin filaments [42]. A study in retinal neurons showed that crosstalk between CDC42 and RhoA occurs upstream of ROCK and reduces the phosphorylation of $\mathrm{ADF} /$ cofilin [43]. In neurons, Toxin B treatment decreased the phosphorylation level of cofilin [14]. The tight connection of CDC42, ROCK, cofilin, and actin led us to explore their possible relationships. Thus, western blotting was employed, which showed that inhibition of CDC42 expression caused a significant decrease in ROCK. The phosphorylation of cofilin was also affected. This indicates that CDC42 affects the actin cytoskeleton by interacting with ROCK and cofilin. In addition, recent studies showed that CDC42 downregulates N-WASP protein [23] for polar body extrusion in mouse oocytes. Our study also showed similar results, which indicates that CDC42 plays conserved roles among mammalian species.

In conclusion, our study illustrates that CDC42 participates in actin-based porcine oocyte maturation via interaction with N-WASP, ROCK, and cofilin.

Conflict of Interest: The authors do not have any conflict of interest to declare.

\section{Acknowledgements}

This work was supported by the National Basic Research Program of China (2014CB138503), the National Natural Science Foundation of China (31622055, 31571547); Natural Science Foundation of Jiangsu Province (BK20140030); the Fundamental Research Funds for the Central Universities, China (KJJQ201501, KJTZ201602, and KJYQ201701); China Postdoctoral Science Foundation (2015M580441); Postdoctoral Fund in Jiangsu Province (1501065B); and the Biogreen 21 Program (PJ011126), RDA, Republic of Korea.

\section{References}

1. Verlhac MH, Lefebvre C, Guillaud P, Rassinier P, Maro B. Asymmetric division in mouse oocytes: with or without Mos. Curr Biol 2000; 10: 1303-1306. [Medline] [CrossRef]

2. Schuh M, Ellenberg J. A new model for asymmetric spindle positioning in mouse oocytes. Curr Biol 2008; 18: 1986-1992. [Medline] [CrossRef]

3. Longo FJ, Chen DY. Development of surface polarity in mouse eggs. Scan Electron Microsc 1984; (Pt2): 703-716. [Medline]

4. Tremoleda JL, Schoevers EJ, Stout TA, Colenbrander B, Bevers MM. Organisation of the cytoskeleton during in vitro maturation of horse oocytes. Mol Reprod Dev 2001; 60: 260-269. [Medline] [CrossRef]

5. Holt JE, Jones KT. Control of homologous chromosome division in the mammalian oocyte. Mol Hum Reprod 2009; 15: 139-147. [Medline] [CrossRef]

6. Fan HY, Sun QY. Involvement of mitogen-activated protein kinase cascade during oocyte maturation and fertilization in mammals. Biol Reprod 2004; 70: 535-547. [Medline] [CrossRef]

7. Van Aelst L, DSouza-Schorey C. Rho GTPases and signaling networks. Genes Dev 1997; 11: 2295-2322. [Medline] [CrossRef]

8. Jaffe AB, Hall A. Rho GTPases: biochemistry and biology. Annu Rev Cell Dev Biol 2005; 
21: 247-269. [Medline] [CrossRef]

9. Moon SY, Zheng Y. Rho GTPase-activating proteins in cell regulation. Trends Cell Biol 2003; 13: 13-22. [Medline] [CrossRef]

10. Bos JL, Rehmann H, Wittinghofer A. GEFs and GAPs: critical elements in the control of small G proteins. Cell 2007; 129: 865-877. [Medline] [CrossRef]

11. Luo L. Rho GTPases in neuronal morphogenesis. Nat Rev Neurosci 2000; 1: 173-180. [Medline] [CrossRef]

12. Qualmann B, Mellor H. Regulation of endocytic traffic by Rho GTPases. Biochem $J$ 2003; 371: 233-241. [Medline] [CrossRef]

13. Symons M, Rusk N. Control of vesicular trafficking by Rho GTPases. Curr Biol 2003; 13: R409-R418. [Medline] [CrossRef]

14. Zulauf L, Coste O, Marian C, Möser C, Brenneis C, Niederberger E. Cofilin phosphorylation is involved in nitric oxide/cGMP-mediated nociception. Biochem Biophys Res Commun 2009; 390: 1408-1413. [Medline] [CrossRef]

15. Brunet S, Verlhac MH. Positioning to get out of meiosis: the asymmetry of division. Hum Reprod Update 2011; 17: 68-75. [Medline] [CrossRef]

16. Cau J, Hall A. Cdc 42 controls the polarity of the actin and microtubule cytoskeletons through two distinct signal transduction pathways. J Cell Sci 2005; 118: 2579-2587. [Medline] [CrossRef]

17. Shi SH, Jan LY, Jan YN. Hippocampal neuronal polarity specified by spatially localized mPar3/mPar6 and PI 3-kinase activity. Cell 2003; 112: 63-75. [Medline] [CrossRef]

18. Gotta M, Abraham MC, Ahringer J. CDC-42 controls early cell polarity and spindle orientation in C. elegans. Curr Biol 2001; 11: 482-488. [Medline] [CrossRef]

19. Barry DM, Xu K, Meadows SM, Zheng Y, Norden PR, Davis GE, Cleaver O. Cdc42 is required for cytoskeletal support of endothelial cell adhesion during blood vessel formation in mice. Development 2015; 142: 3058-3070. [Medline] [CrossRef]

20. Kirjavainen A, Laos M, Anttonen T, Pirvola U. The Rho GTPase Cdc42 regulates hair cell planar polarity and cellular patterning in the developing cochlea. Biol Open 2015; 4: 516-526. [Medline] [CrossRef]

21. Leblanc J, Zhang X, McKee D, Wang ZB, Li R, Ma C, Sun QY, Liu XJ. The small GTPase Cdc42 promotes membrane protrusion during polar body emission via ARP2nucleated actin polymerization. Mol Hum Reprod 2011; 17: 305-316. [Medline] [CrossRef]

22. Bielak-Zmijewska A, Kolano A, Szczepanska K, Maleszewski M, Borsuk E. Cdc42 protein acts upstream of IQGAP1 and regulates cytokinesis in mouse oocytes and embryos. Dev Biol 2008; 322: 21-32. [Medline] [CrossRef]

23. Dehapiot B, Carrière V, Carroll J, Halet G. Polarized Cdc 42 activation promotes polar body protrusion and asymmetric division in mouse oocytes. Dev Biol 2013; 377: 202-212. [Medline] [CrossRef]

24. Wang ZB, Jiang ZZ, Zhang QH, Hu MW, Huang L, Ou XH, Guo L, Ouyang YC, Hou Y, Brakebusch C, Schatten H, Sun QY. Specific deletion of Cdc42 does not affect meiotic spindle organization/migration and homologous chromosome segregation but disrupts polarity establishment and cytokinesis in mouse oocytes. Mol Biol Cell 2013; 24: 3832-3841. [Medline] [CrossRef]

25. Santos RR, Schoevers EJ, Roelen BA. Usefulness of bovine and porcine IVM/IVF models for reproductive toxicology. Reprod Biol Endocrinol 2014; 12: 117. [Medline] [CrossRef]

26. Miyano T, Manabe N. Oocyte growth and acquisition of meiotic competence. Soc Reprod Fertil Suppl 2007; 63: 531-538. [Medline]

27. Ménézo YJ, Hérubel F. Mouse and bovine models for human IVF. Reprod Biomed Online 2002; 4: 170-175. [Medline] [CrossRef]

28. Liu Y, Ma Y, Yang JY, Cheng D, Liu X, Ma X, West FD, Wang H. Comparative gene expression signature of pig, human and mouse induced pluripotent stem cell lines reveals insight into pig pluripotency gene networks. Stem Cell Rev 2014; 10: 162-176. [Medline] [CrossRef]

29. Jarrell VL, Day BN, Prather RS. The transition from maternal to zygotic control of development occurs during the 4-cell stage in the domestic pig, Sus scrofa: quantitative and qualitative aspects of protein synthesis. Biol Reprod 1991; 44: 62-68. [Medline] [CrossRef]

30. Levey IL, Stull GB, Brinster RL. Poly(A) and synthesis of polyadenylated RNA in the preimplantation mouse embryo. Dev Biol 1978; 64: 140-148. [Medline] [CrossRef]

31. Brevini TA, Cillo F, Antonini S, Gandolfi F. Cytoplasmic remodelling and the acquisition of developmental competence in pig oocytes. Anim Reprod Sci 2007; 98: 23-38. [Medline] [CrossRef]

32. Surviladze Z, Waller A, Strouse JJ, Bologa C, Ursu O, Salas V, Parkinson JF, Phillips GK, Romero E, Wandinger-Ness A, Sklar LA, Schroeder C, Simpson D, Noth J, Wang J, Golden J, Aube J. A potent and selective inhibitor of Cdc42 GTPase. In: Probe Reports from the NIH Molecular Libraries Program. Bethesda (MD); 2010. https://www. ncbi.nlm.nih.gov/books/NBK51965/

33. Hsu CR, Pan YJ, Liu JY, Chen CT, Lin TL, Wang JT. Klebsiella pneumoniae translocates across the intestinal epithelium via Rho GTPase- and phosphatidylinositol 3-kinase/ Akt-dependent cell invasion. Infect Immun 2015; 83: 769-779. [Medline] [CrossRef]

34. McNary SM, Athanasiou KA, Reddi AH. Transforming growth factor $\beta$-induced superficial zone protein accumulation in the surface zone of articular cartilage is dependent on the cytoskeleton. Tissue Eng Part A 2014; 20: 921-929. [Medline] [CrossRef]

35. Hall A. Rho GTPases and the actin cytoskeleton. Science 1998; 279: 509-514. [Medline] [CrossRef]

36. Sun SC, Wang ZB, Xu YN, Lee SE, Cui XS, Kim NH. Arp2/3 complex regulates asymmetric division and cytokinesis in mouse oocytes. PLOS ONE 2011; 6: e18392. [Medline] [CrossRef]

37. Zhang Y, Duan X, Cao R, Liu HL, Cui XS, Kim NH, Rui R, Sun SC. Small GTPase RhoA regulates cytoskeleton dynamics during porcine oocyte maturation and early embryo development. Cell Cycle 2014; 13: 3390-3403. [Medline] [CrossRef]

38. Zhong ZS, Huo LJ, Liang CG, Chen DY, Sun QY. Small GTPase RhoA is required for ooplasmic segregation and spindle rotation, but not for spindle organization and chromosome separation during mouse oocyte maturation, fertilization, and early cleavage. Mol Reprod Dev 2005; 71: 256-261. [Medline] [CrossRef]

39. Barcia C, Ros CM, Annese V, Carrillo-de Sauvage MA, Ros-Bernal F, Gómez A, Yuste JE, Campuzano CM, de Pablos V, Fernandez-Villalba E, Herrero MT. ROCK Cdc42-mediated microglial motility and gliapse formation lead to phagocytosis of degenerating dopaminergic neurons in vivo. Sci Rep 2012; 2: 809. [Medline] [CrossRef]

40. Wilkinson S, Paterson HF, Marshall CJ. Cdc42-MRCK and Rho-ROCK signalling cooperate in myosin phosphorylation and cell invasion. Nat Cell Biol 2005; 7: 255-261. [Medline] [CrossRef]

41. Duan X, Liu J, Dai XX, Liu HL, Cui XS, Kim NH, Wang ZB, Wang Q, Sun SC. Rho-GTPase effector ROCK phosphorylates cofilin in actin-meditated cytokinesis during mouse oocyte meiosis. Biol Reprod 2014; 90: 37. [Medline] [CrossRef]

42. Kaji N, Muramoto A, Mizuno K. LIM kinase-mediated cofilin phosphorylation during mitosis is required for precise spindle positioning. J Biol Chem 2008; 283: 4983-4992. [Medline] [CrossRef]

43. Chen TJ, Gehler S, Shaw AE, Bamburg JR, Letourneau PC. Cdc42 participates in the regulation of $\mathrm{ADF} /$ cofilin and retinal growth cone filopodia by brain derived neurotrophic factor. J Neurobiol 2006; 66: 103-114. [Medline] [CrossRef] 